JELTL (Journal of English Language Teaching and Linguistics)

e-ISSN: 2502-6062, p-ISSN: 2503-1848

2019, Vol. 4(2)

www.jeltl.org

\title{
External Factors Causing Students' Difficulties in Listening
}

\author{
Kartika Pratiwi \\ Yogyakarta State University \\ kartikapratiwi05@gmail.com \\ Erna Andriyanti \\ Yogyakarta State University \\ erna.andriyanti@uny.ac.id
}

\begin{abstract}
To become a good speaker, one has to be a good listener because naturally people cannot speak properly before listening first. Listening is an important requirement, and also a basic competence to be a good speaker in English. Listening is not an easy process since one who listens must be able to distinguish between sounds, understand the vocabulary and grammatical structures, as well as interpret the meaning at the same time. Listening in English requires focus and attention yet, in fact, many students tend to have several difficulties to focus in listening practice. The article aims to show the external factors affecting the students' difficulty within each process of listening comprehension. The external factors include the speaker, the context of material, and the physical setting. By adopting qualitative design, it is found that the external factors have the higher potential to influence the students' focus negatively than the students' physical condition and behavior which are known as internal factors. Moreover, through several findings based on the library research, it is revealed that the external factors are linked to each process of listening. Suggestions with the effective ways to resolve the difficulties in listening are provided.
\end{abstract}

Keywords: difficulty, external factors, listening comprehension

JELTL (Journal of English Language Teaching and Linguistics), 4(2), 2019 


\section{INTRODUCTION}

Learning English is a very complex process because it contains four basic competences namely listening, speaking, reading and writing. There are three addition competences namely grammar, vocabulary, and pronunciation. The most important thing that one can do in order to have good ability in English is mastering all of the competences. Listening competence is one of the most important competences which make people get knowledge and information as well as to reach the achievement to communicate with others. Pollard (2008) defines that listening and reading are receptive skills where students capture and understand the language and also interpret the written words.

Listening becomes more difficult than reading because students find it easier to identify the written words than to identify the spoken words. Further, students while reading can reread a phrase or sentence which is different from listening in which the students only get one chance to comprehend the information. Reading activity has no restriction since it depends on the reader who regulates the reading speed while in listening, the speaker or audio that sets the pace. Based on the fact above we can conclude that both listening and reading are the receptive competences in language, but have different levels of difficulty. In reading if we still do not understand the essence of reading, we can reread it. This is very different from listening which can be done with one occasion without being able to repeat it.

Based on the fact there are many people who still cannot understand what others said in English. They are confused when their interlocutors speak fast which causing them didn't understand the utterances. Therefore, listening is not an easy process because it is more difficult than reading. In addition, one who listens must be able to distinguish between sounds, understand vocabulary and grammatical structures, interpret the meaning at the same time. As an interactive skill, listening can be easily mastered by increasing students' effort and practice and also creating the supportive environment. Hattani (2018) mentions that to encounter the $21^{\text {st }}$ century requirements, education system is currently concerned in the empowerment of students' skills both academic such as critical thinking as well as problemsolving, and social skills such as cooperation and creativity.

To do all those activities splendidly, the most basic thing that must be mastered by students is listening. To master listening skills is not easy but it should be understood that being a good listener will make us become good speakers. Rost (2002) states that the key to gain the speaking proficiency is improving the listening proficiency. So that listening is an important requirement to be a good speaker and generally most students still ignore it. Difficulty in mastering listening is certainly influenced by many factors. The factors that influence students' difficulties in listening consist of internal and external factors. Internal factors influencing the listening process are hearing problems and physical conditions. When students have hearing problem or damage of their hearing device which can inhibit the entry of waves in a certain volume, then the listening process will be interrupted. Likewise, if the students are not in good physical condition then they cannot concentrate on listening to other people's speech well.

External factors include environmental factors, material factors, speakers, style and speaking techniques. Learning material can affect the listening process. Listeners will be more interested in new material compared to the old one. The speaker factor can also disrupt 
the attention of listeners. For example, an experienced and calm speaker will be more persuasive than a nervous speaker. Besides that, the style, appearance and technique of material presentation can be one of the factors that influences the listening process such as visualization and technology used. Therefore the writer intends to examine where the difficulties in terms of student external factors.

There are a lot of listening research that focus on internal and external factors causing difficulties of students in English. Here the writer serves various findings in some research about factors influencing students' skills in listening. There is a gap from previous research where the writer tries to not only reveal the external factors causing the difficulty in listening but also to offer the suggestion to resolve that problems. In addition to expressing external factors, the writer also fills the gap that exists from previous research by linking any external factors that influence each listening process. Based on previous research focusing on listening problem, it can be considered as the supported findings to prove that external factors play crucial role in foreign language achievement of listening. The purpose of this article is to describe about the external factors causing the students' difficulty in each of listening process and how to solve the difficulty.

\section{LISTENING COMPREHENSION IN SECOND LANGUAGE LEARNING 2.1 Definition of Listening}

Listening is the first process that every human through in their life naturally without have to learn it formally. Brown (2018) mentions listening in the classroom mostly defined as listening comprehension. As an influential part in the second language learning, listening is a needed skill to get the input in order to produce the language effectively. According to Bentley and Bacon (1996), listening is an active process in which the listener derives oral input and constructs the meaning at the same time. Buck (2001) claims listening as the construction of continuous interpretation toward oral input. Therefore, the ability to regulate the interpretation to respond new information is very important in the second or foreign language listening process. Nunan (2002) states that listening as a receptive skill in which the execution is hard to achieve and both students and teachers require a lot of patience in that process. Even though listening is considered as receptive skill, the process still requires students to listen actively to obtain the understanding.

According to Rost (1994), listening is considered as crucial role in second language because of some reasons. First, listening is a process providing understandable input which is essential for students. Second, interacting with the speaker is required by listener to reach the understanding. Third, students become more interested to new forms in the language obtained from listening exercises. Therefore, listening is a crucial and noteworthy not only as a receptive skill in language learning but also as an equipment required in order to develop the ability of spoken language. In the listening process, understanding the content is the point of the whole activity. Hence, the teachers have to help the students to actively involving themselves in second language listening.

There are two types of listening that students need to understand in order to improve their skills and pronunciation. These kinds of listening are called intensive listening and extensive listening in which to achieve the maximum benefit in English as foreign language listening comprehension. Intensive listening requires students to comprehend every sentence 


\section{Kartika Pratiwi \& Erna Andriyanti}

and word as well as the meaning of each discourse. In general, students need to listen to the text not only once but several times or split the text within paragraph or sentences in order to make the students understand every sentence. Otherwise, extensive listening is discrete with the intensive listening which focus on the meaning of each word. Extensive listening requires students to comprehend the general meaning of the text and sometimes takes place outside the class like in students' home, public transportation, etc.

Gilakjani and Ahmadi (2017) declare that the aim of intensive listening is to construct the students' ability of basic listening while extensive listening aims to substantiate and enhance the effectiveness of intensive listening with an eye to increase listening competence relatively. Due to the frequency of use is higher than other skill, listening is very important skill that students need to increase. Wolvin and Coakley (1988) define that listening is a dominating activity and consumes more time in everyday communication than other verbal communication forms both inside and outside of the classroom.

\subsection{The Process of Listening Comprehension}

Bottom-up process is stimulated by new input which enters the system through the most appropriate lower level of schemata. Gilakjani and Ahmadi (2017) mention that schemata are the leading structures in the process of understanding which are constructed from the most specific at the bottom to the most common at the top. In other words, listening refers to decoding sound process in accomplishing the text started from the smallest meaningful units (fonem) which are translated to construct words. Afterward, the constructed words are continued to compile phrases which are linked together to construct utterances. Thereafter, those utterances are connected to compile the meaningful text. It can be concluded that the arrived meaning is the last move in the process. Thus, Rubin (1994) suggests the listeners to use their comprehension of words, syntax and also grammar to run well in the process of bottom-up. In other words, it is closely related to the listeners' knowledge of linguistics.

Top-down process refers to understanding the meaning of text using background knowledge of the listener. Carrell and Eisterhold (1983) show that top-down process includes the system of making common predictions based on the higher level, general schemata, and then seeking input for information in order to fit with the higher order schemata practically. In listening process, the listeners construct the speaker's original meaning by using new input as a direction. The process of this reconstruction requires the listeners to adopt the prior knowledge of context and situation in which the listening happens in order to conceive what they listen to. The things including in context and situation are the comprehension of the topic, the amount of speaker, and their connection with the situation as well as with the prior occurrences.

The interactive process is presented to overcome the weaknesses of bottom-up and topdown process and also to increase the understanding. In 1980s, Top-down process was known as the only process that can improve the student's comprehension of second language listening. However, both top-down and bottom-up are accepted as the combination in enhancing listening comprehension nowadays. The students feel easy in comprehension and interpretation by entering the information of contextual, linguistic and background 
knowledge. When the listeners feel familiar with the content of the material, they will engage, at the same time, their background knowledge creating predictions that will be shown by the new input. Otherwise, when the listeners feel that the content of material is new and unfamiliar with it, they can use their linguistic knowledge such as lexical and syntactical comprehension in order to understand the information.

Lynch (1998) also highlights the process of listening such as speech recognition, memory in processing, and discourse comprehension. Listening comprehension requires listeners' ability to recognize words and phrases in spoken language and also to construct the meaning derived from the information by the speaker. Speech recognition is the first process in which the listener tries to identify words because spoken words, unlike printed words, revealed over time. To comprehend the spoken language, the listeners need to use prosodic information to activate the words from their memory storage. Understanding the English as foreign language by the listener is influenced by the phonological role of stress from the first language. Memory in processing is the process which is related to linguistic ability. Unlike the first language comprehension, second language comprehension requires the listener to disgorge more resources to grammatical processing. Discourse comprehension is the only way used by listeners to be able to achieve the achievement of real-time processing in which involves constructing meaning from extended parts of language.

\subsection{Listening Problems}

Due to listening comprehension is a continuous process implicating the interaction of many factors, many students feel the difficulty to understand the oral input and do not aware about why it happens to them. Goh (2000) claims that listening difficulties are all things interfering the process of understanding both internal and external. Those characteristics are related to cognitive procedures directly various stages in listening comprehension. By examining the listening problems of ESL learners in Anderson's (1985) three phase model of language comprehension, Goh (2000) mentions that most problems reported by learners were related to the word identification and attention failure. Moreover, Grognet and Van Duzer (2003) discussed that the students' difficulty in listening is linked to many factors such as the listener, the speaker, the content of the material and also the visual support accompanying the listening process.

\subsection{Factors Affecting Listening Comprehension}

There are three characteristics pointed out by Boyle (1984) regarding to the factors affecting listening comprehension. Those characteristics are associated to speaker, listener, material and medium in comprehending English as a foreign language.

\subsubsection{Speaker Characteristic}

Speaker portrays a crucial role in listening comprehension. The speaker becomes determinant factor of listeners' attainment because in addition to understanding the spoken language, listeners must be able to construct the meaning of information obtained from the speaker. There are four items contained in the characteristic of speaker. First, language ability of the speaker impacts the listeners who learn English as the second or foreign language. The listeners tend to prefer non-native speaker as the input provider because of 


\section{Kartika Pratiwi \& Erna Andriyanti}

feeling more in line with their tongue. Second, speaker's production including pronunciation, accent, variation, and voice can make listeners difficult to understand because of many variations from native speaker that they have never heard before. Third, Speed of delivery is other aspect giving big impact especially for low level listeners who feel quite hard to get the meaning of the passage if the input by speaker is given too fast. Forth, the speakers' prestige and personality also affect the listeners' comprehension negatively if the speaker fails in expressing the essence of the text which is a key to comprehend the information.

\subsubsection{Listener Characteristic}

There are a lot of research identifying the listener factor as a crucial impact in listening comprehension. Since listening is a kind of receptive activity and mastering it is the precondition in developing the productive abilities (Usipbekkyz, 2015), it specifically relates to the listener factor concerning to the ability of cognitive aspect which can assist them in comprehending the listening text. Boyle (1988) categorizes the listener characteristic into two factors, general and specific. General factor includes listener's experience or practice in listening to English as a foreign language using media such as cinema, radio, etc., general intelligence, and general background knowledge of the world. Specific factor is related to listener's physical and education consisting of age or sex, home background as well as family size, background of education and school, health and alertness. Other aspect of specific factor involves listener's intellectual which is associated to listener's knowledge of English as a foreign language, the ability to analyze and to determine the specific topic, and also short and long term of memory.

\subsubsection{Material and Medium Characteristic}

Characteristics that also have great influence in listening English as a foreign language are material and medium. Those aspects are located in the outside of listener and some of them are elements in the speaker. The aspects affecting the understanding consist of four items. First, the language used to deliver the message such as stress, intonation, weak forms, lexis, syntax and cohesion. Second, content and concepts can cause the difficulty if the material is abstract, elusive, overly technical, too long and poorly organized. Third, environment refers to noise atmosphere and lots of interference. Forth, other supporting media is also affects the students' focus such as gestures and visuals.

Brown (2001) states eight factors affecting the listeners in listening comprehension. First, clustering words refers to the students' way to associate the words with their meaning. Clustering helps students to choose and understand the controllable clusters of words rather than try to comprehend an entire passage. Second, redundancy is repetition in which students can practice themselves to benefit from it by being aware and by searching for its signals. Third, reduced forms also affect the students to comprehending the information. Forth, Performance variables consist of hesitations, false starts, pauses, ungrammatical forms and dialect differences. Fifth, Colloquial language refers to informal words, idioms, and slang. Sixth, Rate of delivery is crucial to understand when the language delivered varying speeds, sometimes with a few pauses. Seventh, stress, rhythm and intonation are important to be 
understood in which those are conveying the important messages. Eighth, Interaction includes negotiation, clarification, attending signals, turn-taking, and topic nomination.

Furthermore, Rost (2011) listed four factors that affect listener's test performance including medium of the input, nature of the input, nature of the assessment task, and individual listener factors. First, medium of the input refers to video or audio-only presentation or following by graphic or text improvements. Second, nature of the input consists of dialect, speech rate, length, background, prepositional density, and amount of redundancy. Those characteristics can negatively affect the comprehension if the students' are unable to understand or reach it. Third, nature of the assessment task refers to the application of visual context, quantity of context given, explication of instructions, existence of question preview, and kinds of thinking process. Lack of elements in the assessment task also produces negative influence toward students' performance in listening. The last is individual listener factor consisting of recall, readability, background knowledge, motivation, and preparedness to take the test.

From the explanations above, it can be concluded that generally factors affecting the listening process consist of internal and external factors. Internal factors include the listener's performance such as physical condition and hearing problems. The difficulty in comprehension by reason of listeners' memory, interest, background knowledge and motivation belongs to internal factors because of it derived from the listener itself. The external factors refer to elements that come from the outside of listener. The external factor according to Boyle (1984) can be classified into the speaker characteristic, material and medium characteristics. Similarly, Brown (2001) states the same thing about the external factor related to the speaker including rate of delivery, style and speaking technique. Furthermore, Rost (2011) highlights the external factor in listening comprehension such as the material context and physical setting.

\section{EXTERNAL FACTORS AFFECTING LISTENING IN PEDAGOGICAL RESEARCH: WHAT MAKES LISTENING DIFFICCULT?}

\subsection{The Speaker}

The speaker becomes the major factor influencing the students' comprehension in listening. The matters relating to the speaker are speaker's accent, speech rate, style and speaking technique. The way in which words are spoken by the speaker is considered as speaker's style or manner. Moreover Graham (2006) in his study reports that the main problems in listening process are related to the speed of text delivery causing the failure in identifying the input. From his study, the mostly identified problems are the speed of speech and unknown or unfamiliar words discovered by students.

Anandapong (2011) states that students feel complicated and difficult to get the point of listening because of the speaker that spoke too fast. The students' incompetence in listening is also affected by the speakers who speak in the various accents. This is not only happened to students that have English as their Foreign Language but also for those who are the native speakers. This is shown by Hamouda (2013) who claims that some pupils thought they have different versions of English in which their teacher trying to teach them British English at school while they mostly hear American English on television in their home. 


\section{Kartika Pratiwi \& Erna Andriyanti}

In addition, Rajab and Nimehchisalem (2016) also state the students' problem in listening is the listening input, beside the text length, such as speaker's accent and speed of delivery. The students feel uneasy to find out what the speaker means if he speaks quickly without pause it in order to give time for students to comprehend the text. From these findings, it can be concluded that speaker's accent plays a crucial role in the listening process of second language. These findings also strengthen the research of Goh (1992) which also explained that speech quickness is also considered a dominant problem for foreign language learners until now.

In contrast with these findings, Cubalit (2016) states that $93 \%$ of the respondents' problem is affected by difficulty to comprehend the meaning when the native speaker speaking in normal speed and $87 \%$ followed by the difficulty in listening when there are a lot of pauses and doubts in speaking. The manner to pronounce the words is one of the problems faced by foreign language learners. Rajab and Nimehchisalem (2016) show that foreign language learners often find it hard to conceive the vocabulary meaning which is incorrectly pronounced. This finding assented with the Hassan's (2000) findings, in determining students' self-perceived listening problems through a questionnaire, in which unclear pronunciation was identified as the cause of listening problem.

The speaker factor often influences the process of speech recognition and bottom-up processing. The unbalanced and inappropriate of speaker's speed and accent cause the lessening of concentration level to identify the words. The input given is needed to recall the words derived from students' memory to be adjusted to the spoken words. It cannot be run well if the students are not able to reach the speed of the speaker and they do not understand the accent used by the speaker. Since the speaker speaks too fast, the listener has difficulty catching the point of the text. For instances, the listeners are able to capture the information provided in the first sentence but the second sentence is delivered too fast so that it is not captured completely so the listener will get lost.

This matter causing the speech recognition cannot be processed. The listeners who are able to chase the native speaker speed will capture at least $70 \%$ of the meaning of the entire text. This is contributed by many factors such as accents and techniques or speech styles that also affect the delay of the bottom-up process that can be understood as the process of sending language from ear to brain. Listeners are not able to hear completely because they are blocked by some unfamiliar words or sentences so that they cannot send the form of language that is heard to the brain for processing. The accents used by the speaker make listeners are not able to understand the information and cause the inability to answer questions related to what is heard.

As evidenced by more than twenty years being the major factor that makes the students' difficulty in listening, accent and speech rate problems can be solved in various ways. The suggestion to improve students' listening skills referring to the speaker's accent is to make them listening to music or movie in English. By listening to music and watching movie for maximum two hours per day, the students will get used to the accent and also make them more understand what the speaker said. 


\subsection{The Context of Material}

From the research result conducted by Anandapong (2011) in which the participants are Thailand students, listening text is the most influential factor that caused the students' difficulty in listening. This is supported by Chao's (2013) finding about comparing students' listening ability from college of Technology and Education in Taiwan. The result showed both college of Technology students and Education students have problems in listening related to a long listening text and unacquainted words.

In addition, pupils who learn English as their foreign language often find it hard to understand the slang and idiom expression in the listening text. Cubalit (2016) in his research found that students' difficulty in understanding is when speaker using contractions, a shortened version of a word or words, in English such as wanna (want to), gonna (going to) etc. This is also supported by Rajab and Nimehchisalem (2016) in which their findings of listening comprehension problem show that the learners suffered from the input of listening comprehension. The material of listening is also the major factor confusing students in listening. The length of text, for instance, affects the students in which they find many unfamiliar words in the long text.

From these findings, it can be concluded that the length of listening text affects the difficulty in which it contains some unfamiliar vocabularies, slang and idiomatic expression. The context of listening becomes main factor of students' difficulty while listening to English as a foreign language. The context of material, which is highly organized and technical, makes students fail in listening test. This is proven by Kurniawati's (2016) research which shows that the students' difficulty while listening is affected by the material of text. The students feel that the level of material text which high qualification made is too hard to do.

The material context affects the students' listening of bottom-up process and discourse comprehension especially if the position of period is not balance in a paragraph. The process of bottom-up requires students' concentration to interpret the meaning of the text. If students listen to the long text, it will make them difficult to capture the contents or the point of the text. Some students often make a short note about important points of the text to recall what they have heard. This process will be ruin if they are distracted by the lag or delay in understanding the whole text. Discourse comprehension also requires an understanding of every word given. Both of those processes will be disrupted if the text is too long and containing many unfamiliar words.

The period position of text which is not balance to each other certainly makes students feel difficult to understand the meaning of the information. In addition, questions that are made with high levels are sometimes not in accordance with student competencies. Especially tests that are technically made too high will make it difficult for them to identify each word or sentence. So that, the material context should be made based on the students' competence and level of material is not too high and not too low. Well-organized text also decreases students' difficulty in listening because the listeners do not have to spend much time to comprehend a long text followed by unbalanced period. 


\subsection{The Physical Setting}

The physical setting in the classroom is one of important factors affecting the students' focus on listening. According to Rost (2011), medium of the input such as video or audio supports the students in listening comprehension. The well prepared video presentation accompaniment with graphics or text can improve the students' performance. This can affect students to give more attention to listen carefully. It is supported by Treasure (2017) who states that listening is a combination process between hearing and attention. The poor quality of audio causes the provided input unclear inflicting the problem in listening comprehension. This is powered by Chao's (2013) finding which show $62 \%$ students of Technology and Education failed to answer the listening test because of unclear pronunciation.

The noise happening in the process of listening affects the learners' focus to comprehend the material. Kurniawati (2016) found that the noisy situation occurred in classroom is caused by unavailable soundproof system. The lack of soundproof system also makes the sound from the outside come to the class. It means that the students find it difficult to comprehend English as a foreign language when the sounds are unclear. The unclear sounds deriving from poor quality of audio or noisy condition interfere with students' understanding in listening new language.

The noise and poor quality of audio will impact the students' speech recognition and memory in processing. The physical setting also influences the process of speech recognition and interactive processing. Input is very important in listening comprehension and it also depends on the class environment and quality of audio. Students need full concentration when they listen to the native speaker supporting by the audio only. If the audio for the listening process is not clear, the speech recognition will be interrupted. For instance, a form of dialogue in the listening test, students will forget what they have heard previously because of the audio problem. The problem refers to the disturbance in the audio whether it is heard vaguely or audio consisting of additional sounds that are louder than the listening material.

Noise arising from the lack of soundproof devices and the poor quality of audio generates the unclear input. Noise influences the interactive processing where top-down and bottom-up processing need students' concentration. In recognizing the words, a clear input is needed so that poor quality of audio affects the process of speech recognition. The voices heard from the outside of the class are also disturbing the listening process. Students' lack of focus will make them feel oblivious about the content of material. The condition of the class which is near the road or the crowd is also one of the causes of the disruption of students' concentration in listening. The students pay attention to the source of the sound produced, but the following sound of the vehicles, or the sound of people talking or playing music from outside the classroom certainly causes confusion for students to focus on the main sound to be captured.

Suggestion to settle this problem is by preparing tool and place which is appropriate to efficient listening process. The teacher or instructor has to ensure that the audio provided is a good quality and also produce clear sounds. The appropriate place does not mean that the teacher provides deluxe place, but the place where related to students' need to listen effectively without having interference from outside. 


\section{CONCLUSION}

By training and improving the habits, motives and skills in listening comprehension, students are able to increase the listening ability in English. Even though listening ability is determined by the listener itself, but the factors outside the listener are actually determining the success or failure of the listening process. In spite of the students' best condition and preparation, they will find it difficult if the situation around them is not supportive to do the listening process. To deal with the external factors causing the difficulty in listening, both student and teacher have to create some procedures in order to run the listening process well.

The three external factors causing students' difficulty in listening related to the speaker, the context of material and the physical setting can be overcome properly. The suggestion regarding to the deal with those external factors is improving students' skills by listening to music and watching movie to make them get used to the accent and also make them more understand what the speaker said. For the material context, it should be wellorganized and appropriate with students' competence. The physical setting factor can be overcome by preparing a good quality of audio and place which is appropriate to efficient listening process. The teacher needs to provide language-learning situations that raise students' interest, enthusiasm, and focus to maximize the process of listening for comprehending English as a foreign language.

\section{REFERENCES}

Anandapong, S. (2011). A Study of English Listening Problems and Listening Proficiency of Business Students at Bangkok University. A research paper: unpublished. Language Institute, Thammasat University. Bangkok, Thailand.

Bently, S. \& Bacon, S.E. (1996). The all new, state-of-the-art ILA definition of listening:Now that we have it, what do we do with it?. Listening Post. 56, 1-5. Retrieved from https://www.listen.org/resources/Documents/56_Apr_96Spring.pdf

Boyle, J. P . (1984). Factors Affecting Listening Comprehension. ELT Journal. 8(1), 34-38. https://doi.org/10.1093/elt/38.1.34

Brown, H. D. (2001). Teaching by principles: An interactive approach to language pedagogy $\left(2^{\text {nd }}\right.$ ed). New York: Longman.

Brown, S. (2018). Task-Based Approach to Listening. The TESOL Encyclopedia of English Language Teaching. https://doi.org/10.1002/9781118784235.eelt0613

Buck, G. (2001). Assesing Listening. New York: Cambridge University Press.

Carrell, P. L., \& Eisterhold, J. C. (1983). Schema theory and ESL reading pedagogy. TESOL Quarterly, 17(4), 553-573. Retrieved from http://www.jstor.org/stable/3586613

Chao, J. Y. (2013). Factors Affecting College EFL learner's Listening Comprehension and Listening Problems. NCUE Journal of Humanities. 8, 71-84. Retrieved from http://ir.ncue.edu.tw/ir/bitstream/987654321/19865/1/2040000810005.pdf

Cubalit, A. N. (2016). Listening Comprehension Problems of Thai English Learners. Proceedings of the Third International Conference on Language, Literature \& Society. 207-214. Sri Lanka: International Center for Research and Development.

Gilakjani, A. P. \& Ahmadi, M. A. (2017). A Study of Factors Affecting EFL Learners' English Listening Comprehension and the Strategies for Improvement. Journal of 
Kartika Pratiwi \& Erna Andriyanti

Language Teaching and Research. 2(5), 977-988. https://doi.org/10.4304/jltr.2.5.977988

Goh, C. M. (2000). A Cognitive Perspective on Language Learner's Listening Comprehension Problems. System, 28, 55-75. https://doi.org/10.1016/S0346251X(99)00060-3

Graham, S. (2006). Listening comprehension: The learners' perspective. System, 34(2), 165182. https://doi.org/10.1016/j.system.2005.11.001

Grognet, A. \& Van, D. C. (2003). Listening Skills in the Workplace. Center for Applied Linguistics. Retrieved from http://www.springinstitute.org/Files/listeningwkplc.pdf

Hamouda, A. (2013). An Investigation of Listening Comprehension Problems Encountered by Saudi Students in the EL Listening Classroom. International Journal of Academic Research in Progressive Education and Development. 2(2), 113-155.

Hasan, A. (2000). Learners' perceptions of listening comprehension problems. Language, Culture and Curriculum. 13(2), 137-153. https://doi.org/10.1080/07908310008666595

Hattani, H. A. (2018). Communicative Language Teaching in the Moroccan EFL Classroom. Journal of English Language Teaching and Linguistics. 3 (2), 8798. http://dx.doi.org/10.21462/jeltl.v3i2.108

Kurniawati, D. (2016). Studi Tentang Faktor-Faktor Penyebab Kesulitan Belajar Menyimak Bahasa Inggris Pada Mahasiswa Semester III PBI IAIN Raden Intan Lampung Tahun Pelajaran 2015/2016. Bachelor Thesis. IAIN Raden Intan Lampung.

Lynch, T. (1998). Theoretical Perspectives on Listening. Annual Review of Applied Linguistics. 18, 3-19. https://doi.org/10.1017/S0267190500003457

Nunan, D. (2002). Listening in language learning. In J. C. Richards, \& W. A. Renandya, (Eds.), Methodology in language teaching: An anthology of current practice. Cambridge: Cambridge University Press.

Pollard, L. (2008). Teaching English. UK: Longman.

Rajab, S.Y. \& Nimehchisalem, V. (2016). Listening Comprehension Problems and Strategies among Kurdish EFL Learners. The Iranian EFL Journal. 12(4), 6-27. Retrieved from http://psasir.upm.edu.my/id/eprint/54719

Rost, M. (1994). Introducing listening. London: Penguin books.

Rost, M. (2002). Teaching and researching listening. London: Longman.

Rost, M. (2011). Teaching and Researching Listening: (2 ${ }^{\text {nd }}$ ed.). Britain: Pearson Education Limited.

Rubin, J. (1994). A review of second language listening comprehension research. The Modern Language Journal, 78(2), 199-221. Retrieved from http://www.jstor.org/stable/329010

Treasure, J. (2017). How to be Heard: Secrets for Powerful Speaking and Listening. USA: Mango Publishing Group.

Usipbekkyzy, B. Z. (2015). Section 5. Language and Literacy Learning. European journal of education and applied psychology. 20-24. Retrieved from https://booksc.xyz/book/50498830/9bebd0

Wolvin, A. D., \& Coakley, C. G. (1988). Listening ( $3^{\text {rd }}$ ed.). Dubuque, IA: Wm. C. Brown. 